\title{
Inguinal hernia repair - TEP or TAPP?? A comparative analysis between both the laparoscopic procedures in a tertiary care center
}

\author{
Atia Zaka Ur Rab', Sheikh Saif Alim², Wasif Mohammad Ali ${ }^{3}$, Syed Amjad Ali Rizvi ${ }^{4}$ \\ ${ }^{1,4}$ Professor, ${ }^{2}$ Junior Resident, ${ }^{3}$ Assistant Professor, Department of Surgery, Jawaharlal Nehru Medical College and \\ Hospital, AMU, Aligarh
}

Background: Inguinal hernia surgery is one of the most common elective procedures performed by the surgeons and has evolved from open to the laparoscopic technique. Aims and Objectives: This prospective study was conducted to find out intra-operative and post-operative outcomes in patients undergoing TEP and TAPP for inguinal hernia repair. Materials and Methods: A prospective study was conducted on 50 adult patients who underwent laparoscopic inguinal hernia repair between November 2017 to November 2018. It was a randomized study and equal number of patients were allocated to TAPP and TEP group based on the surgeon's preference. Results: Operative time [p<0.0001], intensity of pain (VAS) was significantly higher in TAPP compared to TEP in the immediate post-operative period (6 hours) and during hospital stay $[p=0.0299]$. No significant difference observed in VAS between TEP and TAPP during follow up [after 1 week $(p=0.2298), 2$ weeks $(p=0.2337)$, and 4 weeks $(p=0.3944)]$. Both TEP and TAPP were comparable in terms of Intra-operative and Post-operative complications \{seroma [during hospital stay $(p=0.1573)$, after 1 week $(p=0.6375)$, after 2 weeks $(p=0.5513)$ ]; haematoma [during hospital stay $(p=0.1492)$, after 1 week $(p=0.3125)]\}$ and Conversion $(p=0.3125)$, and Length of hospital stay $(p=0.3960)$. Time to resume normal work $[p<0.0001]$ was significantly more in TAPP than TEP. Conclusion: TEP has a definite edge over TAPP taking into consideration the lesser intensity of post-operative pain during hospital stay, shorter duration of surgery and relatively early return to normal work associated with the former procedure. TEP should therefore be regarded as the procedure of choice for inguinal hernia repair.

Key words: Hernioplasty; Inguinal hernia repair; Laparoscopic hernia repair; TAPP; TEP

\section{Access this article online}

\section{Website:}

http://nepjol.info/index.php/AJMS DOI: 10.3126/ajms.v11i6.30776

E-ISSN: 2091-0576

P-ISSN: 2467-9100

Copyright (c) 2020 Asian Journal of Medical Sciences

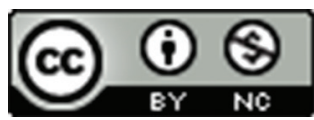

This work is licensed under a Creative Commons Attribution-NonCommercial 4.0 International License.

\section{INTRODUCTION}

The lifetime risk of development of groin hernias is $27 \%$ for men and $3 \%$ for women. ${ }^{1}$ Inguinal hernia surgery is one of the most common elective procedures performed by surgeons. The main goals of any hernia surgery are to reduce the intraoperative and postoperative complication rates, achieving effective repair, lowest possibility of recurrence, rapid return to normal life, cost effectiveness, and better cosmetic results. To successfully achieve these goals, the technique of herniorrhaphy has progressed from open to laparoscopic techniques like Trans Abdominal Pre-Peritoneal (TAPP) and Totally Extraperitoneal (TEP) repair, performed by experienced minimal access surgeons worldwide. ${ }^{2-4,5}$

With the advent of minimal access surgery, hernioplasty is now being done either by TAPP or TEP. Although in earlier studies it had been observed that TEP was relatively difficult and usually took longer time to perform than TAPP probably due to the difficult anatomy of the inguinal region, ${ }^{6}$ the advantage of one procedure over the other remains controversial. 
This prospective study was conducted to find out the intra-operative incidents and post-operative outcomes of TEP and TAPP for inguinal hernia repair in terms of operative time, intra-operative complications, conversion to open surgical repair, post-operative pain, post-operative complications, length of hospital stay, time to resume normal work and short term recurrence of the hernia.

\section{MATERIAL AND METHODS}

A prospective study was conducted on 50 adult patients having unilateral inguinal hernia undergoing elective laparoscopic hernia repair between November 2017 to November 2018. The patients were randomized into two equal groups of 25 patients each who underwent either TEP or TAPP.

Patients having bilateral hernias, recurrent inguinal hernia or those undergoing emergency surgery were excluded from the study.

The operative time, intra-operative complications and conversion to open surgical repair were noted in TEP and TAPP groups. Post-operatively all patients were evaluated for pain which was calculated using Wong-Baker facial pain rating scale ${ }^{7}$ and Visual analogue scale in the immediate post-operative period (at $6 \mathrm{hrs}$ ) and also during the whole length of the hospital stay. All the patients were called for follow-up at 1 week, 2 weeks, 4 weeks, 2 months, 4 months and 6 months. Data was collected regarding post-operative complications viz., seroma, hematoma, wound/mesh infection, length of hospital stay, time to return to normal work and recurrence.

Statistical analysis was done using SPSS software version $20^{\circledR}$. Results on continuous measurements were presented with mean and standard deviation and results on categorical measurements were presented in numbers and percentages. Pearson's chi (x2) square test and Unpaired ' $\mathrm{t}$ ' test were used for statistical analysis. A probability value of less than 0.05 $(p=<0.05)$ was deemed statistically significant.

\section{RESULTS}

All the patients were male and the majority of them (in both groups) were between 21 to 40 years. The two groups were comparable with respect to the age, laterality and type of inguinal hernia. The mean age of patients in TEP group was $41.44 \pm 15.52$ years and that in TAPP group was 40.60 \pm 17.44 years $[\mathrm{p}=0.8580]$ (Table $1 \mathrm{a})$.

Indirect inguinal hernia was present in $18(72 \%)$ patients in the TEP group and $14(56 \%)$ patients in TAPP group. $7(28 \%)$ patients in the TEP group and $11(44 \%)$ patients in TAPP group had direct inguinal hernia $[\mathrm{p}=0.2384]$. In TEP group, $16(64 \%)$ patients had right-sided hernia as compared to $15(60 \%)$ patients in TAPP group [ $\mathrm{p}=0.7708]$ (Table 1a).

The mean operative time was significantly lesser in the TEP group [83.40 \pm 5.61 minutes, $\mathrm{SD}=5.61, \mathrm{SEM}=1.12]$ than in the TAPP group [ $97.76 \pm 7.84$ minutes, $\mathrm{SD}=7.84$, $\mathrm{SEM}=1.57][\mathrm{p}<0.0001]$ (Table 1a).

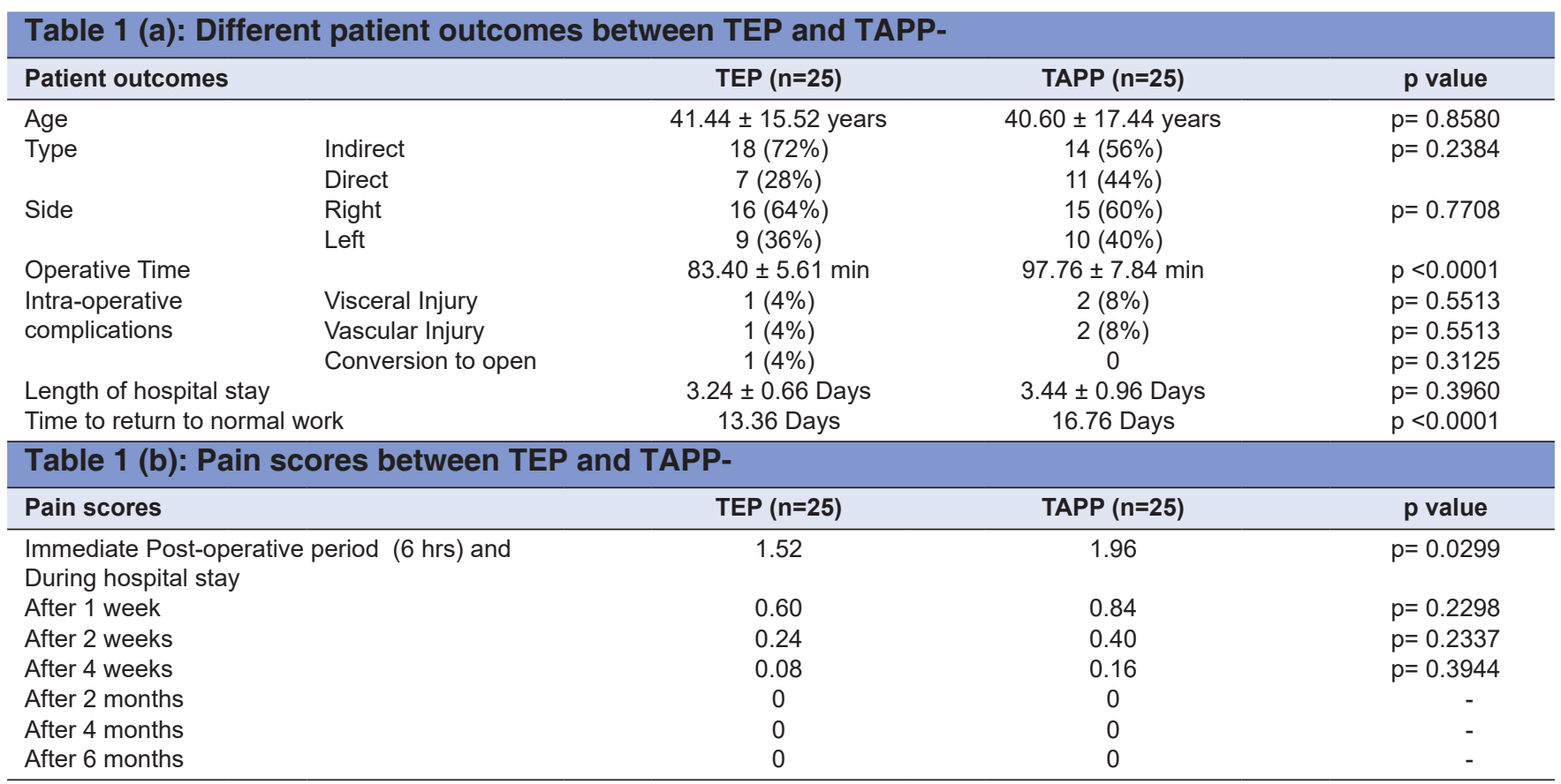


Visceral injury occurred in $1(4 \%)$ patient during TEP and in $2(8 \%)$ patients during TAPP [ $\mathrm{p}=0.5513]$. Vascular injury occurred in $1(4 \%)$ patient undergoing TEP and $2(8 \%)$ patients during TAPP $[\mathrm{p}=0.5513]$. All cases undergoing TAPP repair were successfully performed, and $1(4 \%)$ case undergoing TEP had to be converted to open surgical repair $[\mathrm{p}=0.3125]$. No statistically significant difference was found between the complication rates of the two groups (Table 1a).

No statistically significant difference $[\mathrm{p}=0.3960]$ was found between the mean length of hospital stay in the TEP group [3.24 days $(\mathrm{SD}=0.66, \mathrm{SEM}=0.13)]$ as compared TAPP group [3.44 days $(\mathrm{SD}=0.96, \mathrm{SEM}=0.19)]$ (Table 1a).

Time to return to normal work, however, was found to be significantly longer in patients undergoing TAPP as compared to TEP hernia mesh repair $[\mathrm{p}<0.0001]$ (Table 1a). None of the patients developed recurrence during the course of the study.

Patients who underwent TAPP [Mean $=1.96, \mathrm{SD}=0.79]$ had more pain $[\mathrm{p}=0.0299]$ than those undergoing TEP [Mean $=1.52, \mathrm{SD}=0.59]$ in the immediate post-operative period (6 hrs) and during hospital stay. However, the difference in VAS between the two procedures was not found to be statistically significant after 1 week, 2 weeks, 4 weeks, 2 months, 4 months and 6 months of discharge (Figure 1, Table 1b).

\section{Post-operative complications}

None of the patients in either group had wound/ mesh infection found during the entire course of the study. Seroma formation during the hospital stay in the postoperative period occurred in 1 patient in the TEP group and in 4 patients who had TAPP repair. Seroma was detected in 2 patients after 1 week and in 1 patient after 2 weeks post-discharge in the TEP group. In the TAPP group, seroma formation was detected in 3 patients after 1 week and in 2 patients after 2 weeks of discharge. The difference in the occurrence of seroma formation between the 2 groups was not found to be statistically significant (Table 2).

None of the patients in the TEP group had postoperative haematoma. In the TAPP group, haematoma was found in 2 patients during the hospital stay, and in 1 patient after 1 week of discharge. The difference in the occurrence of haematoma formation between the 2 groups was not found to be statistically significant (Table 2).

\section{DISCUSSION}

In our study, the duration of surgery was 75-95 min in TEP group and 88-117 min. in TAPP group and the mean operative time was found to be significantly longer in TAPP [97.76 \pm $7.84 \mathrm{~min}]$ than in TEP [83.40 $\pm 5.61 \mathrm{~min}]$ group $[\mathrm{p}<0.0001]$.

\begin{tabular}{|c|c|c|c|c|}
\hline & & $\begin{array}{c}\text { TEP } \\
(n=25)\end{array}$ & $\begin{array}{c}\text { TAPP } \\
(n=25)\end{array}$ & $p$ value \\
\hline \multirow{4}{*}{$\begin{array}{l}\text { During hospital } \\
\text { Stay } \\
\text { After } 1 \text { week }\end{array}$} & Seroma & 1 & 4 & $p=0.1573$ \\
\hline & Haematoma & 0 & 2 & $p=0.1492$ \\
\hline & Seroma & 2 & 3 & $p=0.6375$ \\
\hline & Haematoma & 0 & 1 & $p=0.3125$ \\
\hline \multirow[t]{2}{*}{ After 2 weeks } & Seroma & 1 & 2 & $p=0.5513$ \\
\hline & Haematoma & 0 & 0 & - \\
\hline \multirow[t]{2}{*}{ After 4 weeks } & Seroma & 0 & 0 & - \\
\hline & Haematoma & 0 & 0 & - \\
\hline \multirow[t]{2}{*}{ After 2 months } & Seroma & 0 & 0 & - \\
\hline & Haematoma & 0 & 0 & - \\
\hline \multirow[t]{2}{*}{ After 4 months } & Seroma & 0 & 0 & - \\
\hline & Haematoma & 0 & 0 & - \\
\hline \multirow[t]{2}{*}{ After 6 months } & Seroma & 0 & 0 & - \\
\hline & Haematoma & 0 & 0 & - \\
\hline
\end{tabular}

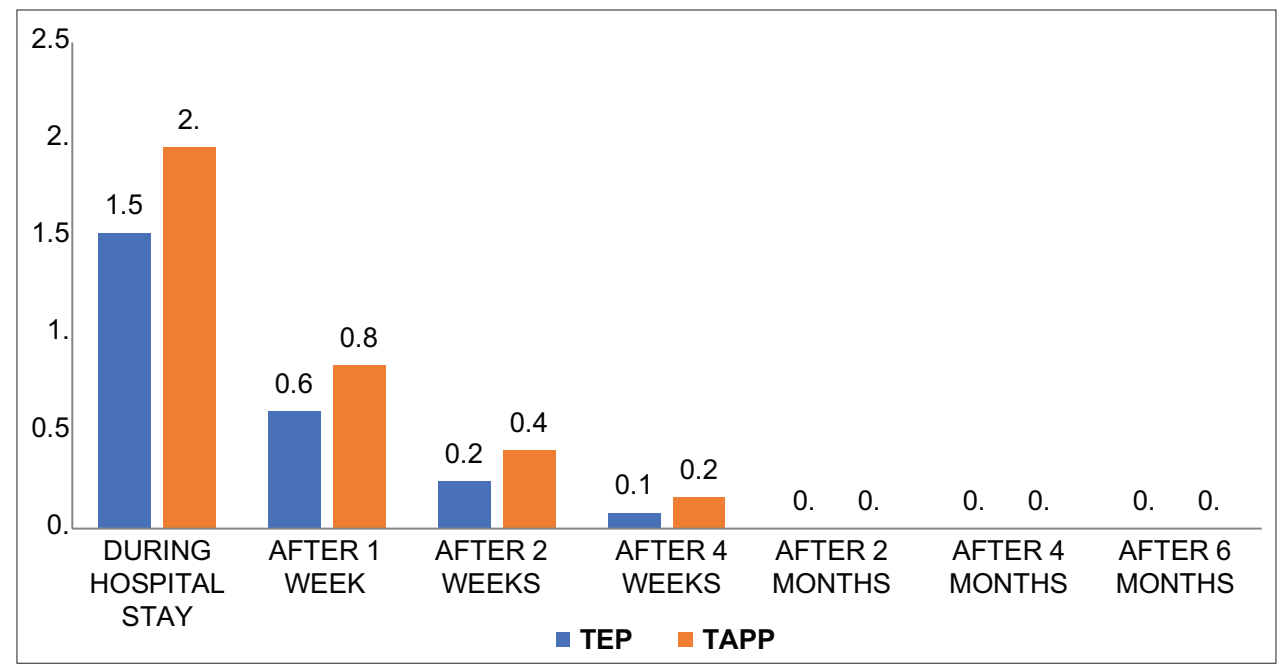

Figure 1: Bar Diagram showing visual analogue scale score between both the groups 
In several studies, however, the duration of operation was found to be 55-95 $\mathrm{min}$ for TEP and 40-70 min for TAPP. ${ }^{8-12}$

In our study, we found that no case from TAPP group was converted to open whereas one case from TEP group was converted to open but the difference in the conversion rate between the 2 groups was not statistically significant $[\mathrm{p}=0.3125]$. The rate of conversion to open surgery in our study was comparable to several other studies. ${ }^{13-16}$ Many studies have compared the rates of conversion between TAPP and TEP procedure to be $0 \%$ versus $4 \%, 0 \%$ versus $1.8 \%$, and $5 \%$ versus $7 \%$, respectively. ${ }^{13-15}$ However, in the large case series the conversion rates between TAPP and TEP were very similar at $0.24 \%$ and $0.23 \%$ respectively. ${ }^{16}$

Although pain scores in the immediate postoperative period in both the TEP and TAPP procedures have been found to be similar in several studies, ${ }^{5,17}$ we found that patients who underwent TAPP had significantly more pain $[\mathrm{p}=0.0299]$ than those undergoing TEP in the immediate post-operative period $(6 \mathrm{hrs})$ and during the hospital stay. The difference in VAS during follow up between the two procedures, however, was found to be comparable after 1 week, 2 weeks, 2 months, 4 months and 6 months of discharge. Several authors have also found no significant difference in the Visual analogue score between the two groups during the follow-up period. ${ }^{5,17}$

Seroma formation has been reported to be the most common complication after laparoscopic inguinal hernia repair ${ }^{18}$ and can become a significant cause of concern for the patients. The incidence of seroma has been commonly reported to range from $1.9 \%$ to $11 \%$ patients undergoing laparoscopic inguinal hernia repair ${ }^{18}$ but it can be as high as $41 \%$ during the initial few days. ${ }^{18}$ In our study, 1 (4\%) patient had developed seroma during the hospital stay, $2(8 \%)$ patients after 1 week and 1 (4\%) patient after 2 weeks of discharge in patients undergoing TEP repair for inguinal hernia. In the TAPP group seroma formation occurred in $4(16 \%)$ patients during the hospital stay, $3(12 \%)$ patients after 1 week and $2(8 \%)$ patients after 2 weeks of discharge respectively. No occurrence of seroma was found in both the groups after 4 weeks, 2 months, 4 months and 6 months of discharge. We did not find any statistically significant difference in the occurrence of seroma formation between the patients undergoing TEP or TAPP. In our study in patients undergoing TAPP, haematoma at the surgical site was detected in $2(8 \%)$ patients during hospital stay and $1(4 \%)$ patient after 1 week of discharge while none of the patients in TEP group developed haematoma. The difference in haematoma formation between the two groups was not found to be statistically significant. In many studies, the incidence of deep mesh infection varies between 0 and $0.2 \%$ in $\mathrm{TAPP}^{19,20}$ and 0 and $0.02 \%$ in $\mathrm{TEP}^{19,21}$ group but none of the patients in our study had any evidence of infection.
It was found by Bracale et al. and Gass et al. in their metaanalysis that there was significantly longer post-operative hospital stay in the TAPP group 22,23 as compared to TEP group. in our study, however, no significant difference was found in the post-operative length of hospital stay in either group $[\mathrm{p}=0.3960]$.

In our study, time to return to normal work was found to be significantly longer in TAPP as compared to TEP hernia mesh repair $[\mathrm{p}<0.0001]$. In several studies, however, no difference in the resumption of normal activities has been observed between the two techniques. ${ }^{13,15,24}$

Recurrence is the important endpoint of any hernia surgery ${ }^{25}$ and requires proper and complete knowledge of anatomy and better technique of repair to keep the recurrence to a minimum. ${ }^{26,27}$ Previously reported incidence of recurrence in TEP was approximately $1-2 \%$ and for TAPP approximately $0-3 \% .{ }^{28}$ In our study, till now no recurrence of hernia was found in either TEP group or TAPP group during short term follow up (i.e. 6 months).

\section{CONCLUSION}

TEP besides being associated with significantly lesser postoperative pain during the hospital stay, has a definite advantage over TAPP as the duration of surgery and the time to return to normal activity is markedly longer in patients undergoing the latter procedure for inguinal hernia repair. TEP should, Therefore, be regarded as the procedure of choice for inguinal hernia repair.

\section{REFERENCES}

1. Primatesta $P$ and Goldacre MJ. Inguinal hernia repair; incidence of elective and emergency surgery, readmission and mortality. Int J Epidemiol. 1996; 25:835-839. https://doi.org/10.1093/ije/25.4.835

2. Arregui ME, Davis CJ, Yucel $O$ and Nagan RF. Laparoscopic mesh repair of inguinal hernia using a preperitoneal approach: a preliminary report. Surg Laparosc Endosc. 1992; 2:53-58.

3. Dion YM and Morin J. Laparoscopic inguinal herniorrhaphy. Can J Surg. 1992; 35: 209-212.

4. McKernan B. Laparoscopic pre-peritoneal prosthetic repair of inguinal hernias. Surgical Rounds. 1992; 7: 579-610.

https://doi.org/10.1007/BF00591232

5. Gong K, Zhang N, Lu Y, Zhu B, Zhang Z, Du D, et al. Comparison of the open tension-free mesh-plug, transabdominal preperitoneal (TAPP), and totally extraperitoneal (TEP) laparoscopic techniques for primary unilateral inguinal hernia repair: A prospective randomized controlled trial. Surg Endosc. 2011; 25:234-239.

https://doi.org/10.1007/s00464-010-1165-0

6. Lal P, Kajla RK, Chander J and Ramteke VK. Laparoscopic total extraperitoneal (TEP) inguinal hernia repair: Overcoming the learning curve. Surg Endosc. 2004; 18:642-645. 
7. Wong $\mathrm{DL}$, Hockenberry $\mathrm{M}$, Wilson $\mathrm{D}$, Winkelstein $\mathrm{ML}$ and Schwartz P. Essential of pediatric nursing. Ed 6 St. Louis; 2001:1301.

https://doi.org/10.1007/s00464-002-8649-5

8. Aeberhard $\mathrm{P}$, Klaiber $\mathrm{C}$, Meyenberg A, Osterwalder A and Tschudi J. Prospective audit of laparoscopic totally extraperitoneal inguinal hernia repair: A multicenter study of the Swiss association for laparoscopic and thoracoscopic surgery (SALTC). Surg Endosc. 1999; 13:1115-1120. https://doi.org/10.1007/s004649901185

9. Lau H, Patil NG, Yuen WK and Lee F. Learning curve for unilateral endoscopic totally extraperitoneal (TEP) inguinal hernioplasty. Surg Endosc. 2002; 16:1724-1728. https://doi.org/10.1007/s00464-001-8298-0

10. Leibl BJ, Schmedt CG, Ulrich $M$, Kraft $K$ and Bittner $R$. Laparoscopic hernia therapy (TAPP) as a teaching operation. Chirurg. 2000; 71:939-942.

https://doi.org/10.1007/s001040051159

11. Liem MS, van Steensel CJ, Boelhouwer RU, Weidema WF, Clevers GJ, Meijer WS, et al. The learning curve for totally extraperitoneal laparoscopic inguinal hernia repair. Am J Surg. 1996; 171:281-285 https://doi.org/10.1016/S0002-9610(97)89569-4

12. Wright $D$ and O'Dwyer PJ. The learning curve for laparoscopic hernia repair. Semin Laparosc Surg. 1998; 5:227-232. https://doi.org/10.1177/155335069800500405

13. Cohen RV, Alvarez G, Roll S, Garcia ME, Kawahara N, Schiavon CA, et al. Transabdominal or totally extraperitoneal laparoscopic hernia repair? Surg Laparosc Endosc, 1998; 8:264-268.

14. Felix EL, Michas CA and Gonzalez MH. Laparoscopic hernioplasty. TAPP vs TEP. Surg Endosc. 1995; 9:984-989. https://doi.org/10.1007/BF00188456

15. Van Hee R, Goverde P, Hendrickx L, Van der Schelling G and Totté E. Laparoscopic transperitoneal versus extraperitoneal inguinal hernia repair: A prospective clinical trial. Acta Chir Belg. 1998; 98:132-135.

16. Tamme C, Scheidbach H, Hampe C, Schneider C and Köckerling F. Totally extraperitoneal endoscopic inguinal hernia repair (TEP). Surg Endosc. 2003; 17:190-195. https://doi.org/10.1007/s00464-002-8905-8

17. Lepere $M$, Benchetrit $S$, Debaert $M$, Detruit $B$, Dufilho $A$, Gaujoux D, et al. A multicentric comparison of transabdominal versus totally extraperitoneal laparoscopic hernia repair using PARIETEX meshes. JSLS. 2000; 4:147-153.

18. Mahesh C. Misra, Kumar S and Bansal VK. Total extraperitoneal (TEP) mesh repair of inguinal hernia in the developing world: comparison of low-cost indigenous balloon dissection versus direct telescopic dissection: a prospective randomized controlled study. Surg Endosc. 2008;22: e1947-e1958. https://doi.org/10.1007/s00464-008-9897-9

19. Baca I, Schultz C, Gotzen V, et al. Laparoscopic inguinal hernia repair. A review of 2500 cases. In: Lomanto D, Kum CK, So JBY, Goh PMY (eds) Proceedings of 7th world congress of endoscopic surgery; 2000 June 1-4; Singapore. Monduzzi editore, Bolonga, Italy, 2001. P. 425-430.

20. Lehr SC and Schuricht AL. A minimally invasive approach for treating postoperative seromas after incisional hernia repair. JSLS. 2001; 5: e267- e271.

21. Tamme C, Scheidbach H, Hampe C, Schneider C, Köckerling F. Totally extraperitoneal endoscopic inguinal hernia repair (TEP). Surg Endosc. 2003; 17: e190- e195. https://doi.org/10.1007/s00464-002-8905-8

22. Bracale U, Melillo P, Pignata G, Di Salvo E, Rovani M, Merola G, et al. Which is the best laparoscopic approach for inguinal hernia repair: TEP or TAPP? A systematic review of the literature with a network meta-analysis. Surg Endosc. 2012; 26:3355-3366. https://doi.org/10.1007/s00464-012-2382-5

23. Gass M, Banz VM, Rosella L, Adamina M, Candinas D and Güller U. TAPP or TEP? Population-based analysis of prospective data on 4,552 patients undergoing endoscopic inguinal hernia repair. World J Surg. 2012; 36:2782-2786 https://doi.org/10.1007/s00268-012-1760-4

24. Schrenk $P$, Woisetschläger $R$, Rieger $R$ and Wayand $W$. Prospective randomized trial comparing postoperative pain and return to physical activity after transabdominal preperitoneal, total preperitoneal or Shouldice technique for inguinal hernia repair. Br J Surg. 1996; 83:1563-1566.

https://doi.org/10.1002/bjs.1800831124

25. Moreno-Egea A, Aguayo JL and Canteras M. Intraoperative and postoperative complications of totally extraperitoneal laparoscopic inguinal hernioplasty. Surg Laparosc Endosc Percutan Tech. 2000; 10:30-33. https://doi.org/10.1097/00129689-200002000-00007

26. Lau H, Patil NG, Yuen WK and Lee F. Prevalence and severity of chronic groin pain after endoscopic totally extraperitoneal inguinal hernioplasty. Surg Endosc. 2003; 17:1620-1623. https://doi.org/10.1007/s00464-002-8798-6

27. Bringman S, Ek A, Haglind E, Heikkinen T, Kald A, Kylberg F, et al. Is a dissection balloon beneficial in totally extraperitoneal endoscopic hernioplasty (TEP)? A randomized prospective multicenter study. Surg Endosc. 2001; 15:266-270. https://doi.org/10.1007/s004640000367

28. Wake BL, McCormack K, Fraser C, Vale L, Perez $\mathrm{J}$ and Grant AM. Transabdominal pre-peritoneal (TAPP) vs totally extraperitoneal (TEP) laparoscopic techniques for inguinal hernia repair. Cochrane Database Syst Rev. 2005; CD004703. https://doi.org/10.1002/14651858.CD004703.pub2

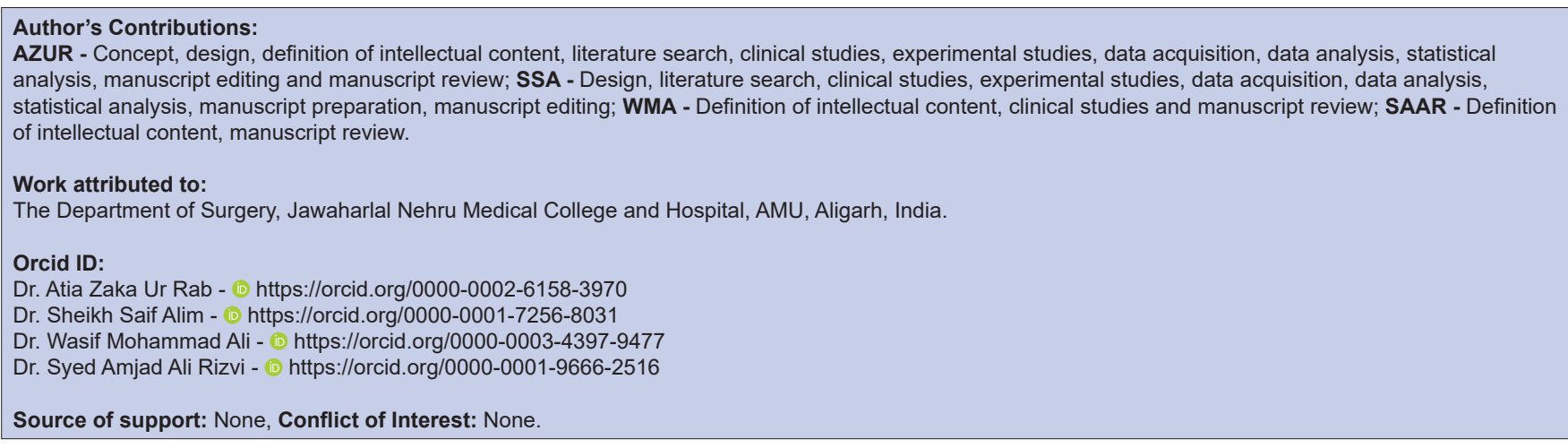

